\title{
O emprego de testes de factualidade em advérbios modais
}

DOI: http://dx.doi.org/10.21165/el.v48i2.2320

\section{George Henrique Nagamura'}

\section{Resumo}

O presente trabalho tem como objetivo examinar a aplicação de testes de copredicação propostos por Saurí (2008) para classificação deadvérbios modais no português brasileiro, seguindo a definição de modalidade proposta por Narrog (2005). A partir de enunciados extraídos do Córpus do Português (DAVIES, 2016), foram analisados três advérbios considerados modais em gramáticas descritivas: francamente, quase e obrigatoriamente. O resultado da análise aponta para os testes de copredicação como uma ferramenta possível para a classificação de advérbios modais, utilizando-se o conceito de modalidade como suspensão da factualidade, fornecendo critérios objetivos para sua determinação, ao mesmo tempo, permitindo a problematização desse conceito, avançando os estudos nesse campo.

Palavras-chave: modalidade; advérbios; factualidade.

1 Universidade Federal de São Carlos (UFSCar), São Carlos, São Paulo, Brasil; genaga.trad@gmail.com; https://orcid.org/0000-0003-1820-6587 


\title{
The application of factuality tests in modal adverbs
}

\begin{abstract}
The objective of the present paper is to examine the application of copredication tests proposed by Saurí (2008) to the classification of modal adverbs in Brazilian Portuguese, following Narrog's (2005) definition of modality. Using occurrences extracted from Córpus do Português (DAVIES, 2006), three adverbs considered as modals in Brazilian descriptive grammars were analyzed: francamente ('frankly'), quase ('almost') and obrigatoriamente ('obligatorily'). The results of the analysis point to copredication tests being a possible tool for the classification of modal adverbs, based on the concept of modality as suspension of factuality, providing objective criteria to its determination, at the same time allowing the problematization of such concept, advancing the studies in this field.
\end{abstract}

Keywords: modality; adverbs; factuality.

\section{Introdução ${ }^{2}$}

O presente trabalho tem como objetivo examinar a aplicação de testes de copredicação, conforme propostos por Saurí (2008) na classificação de advérbios modais no português brasileiro. Na primeira seção, explica-se o conceito de modalidade, seguindo o percurso estabelecido por Narrog (2005). Na segunda seção, são apresentados os testes de copredicação (SAURÍ, 2008). Em seguida, na terceira seção, é apresentada a análise de três advérbios modais utilizando-se os testes previamente mencionados. Por fım, são realizadas as considerações finais.

\section{Modalidade}

A definição de modalidade não é tarefa fácil. Como nos adverte Narrog (2005, p. 165, tradução nossa), "dificilmente há uma categoria gramatical para a qual foram dadas definições mais divergentes, com uma gama tão variada de fenômenos sendo estudados sob seu rótulo"3. Van der Auwera e Plungian (1998), por outro lado, também advertem que há diversas formas de definir a modalidade, não havendo apenas uma forma correta, sendo apenas necessário que se deixe claro como cada um utiliza suas definições.

20 presente trabalho foi realizado com apoio da Coordenação de Aperfeiçoamento de Pessoal de Nível Superior - Brasil (CAPES) - Código de Financiamento 001.

3 No original: "There is hardly any grammatical category which has been given more diverging definitions, and under the label of which a wider range of phenomena has been studied.". 
De acordo com Narrog (2005), a modalidade costuma ser definida de três modos diferentes: 1) modalidade como expressão da atitude do falante, ou de sua subjetividade (ex: LYONS, 1968, 1977; PALMER, 1986); 2) modalidade como uma expressão linguística fora da proposição (ex: FILLMORE, 1968); e 3) modalidade como expressão de distinções de factualidade (KIEFER, 1997; PAPAFRAGOU, 2000; PALMER, 1998, 2001). Embora Narrog (2005) conceda, assim como van der Auwera e Plungian (1998), que não há apenas uma definição correta para a modalidade, o autor defende ser possível demonstrar que algumas definições servem melhor a seus propósitos do que outras.

Com relação à definição de modalidade como expressão de subjetividade, o autor aponta para o fato de que a subjetividade é pervasiva em todo uso da linguagem, desde a escolha lexical, passando por uma série de estratégias gramaticais, como os honoríficos e o uso da voz passiva, chegando a traços não-segmentais, como a prosódia. A desvantagem dessa definição para a caracterização de uma categoria gramatical é óbvia: sendo a subjetividade pervasiva na linguagem, não haveria item linguístico que não fizesse parte da modalidade, sendo qualquer tentativa de classificação completamente arbitrária.

Com relação à segunda definição, Narrog (2005) esclarece que o conceito de modalidade como algo não-proposicional foi originalmente desenvolvido por Fillmore (1968) não como uma categoria gramatical, mas como um meio para identificar um novo constituinte da sentença em sua teoria: a proposição. Fillmore (1968, p. 44) define a proposição como "um conjunto de relações envolvendo verbos e nomes não especificados com relação ao tempo" e todos outros elementos (como negação, tempo, aspecto) pertenceriam à modalidade. Uma das desvantagens da reinterpretação da modalidade proposta por Fillmore como uma categoria gramatical é a contradição de colocar-se a modalidade como uma categoria no mesmo nível da negação, aspecto e tempo, por exemplo, e, ao mesmo tempo, incluir essas mesmas categorias dentro da categoria da modalidade. Ainda segundo Narrog (2005, p. 189), essa reinterpretação da modalidade de Fillmore como uma categoria gramatical "transformou a modalidade na 'lixeira' das categorias gramaticais", ou seja, tudo aquilo que os pesquisadores não soubessem como classificar seria classificado como modal.

A terceira definição, por outro lado, parece servir melhor para o propósito de criar uma categoria gramatical no mesmo nível de categorias como tempo, aspecto e negação. Segundo Narrog (2005), embora as noções de factualidade, realidade ou validade tivessem sido empregadas anteriormente por autores como Lyons (1977) e Palmer (1986), pode-se perceber atualmente uma tendência a não tratar mais essas noções como acessórias à noção de subjetividade ou atitude do falante. Por exemplo, Kiefer (1997, p. 243, tradução nossa), embora reconheça a importância do sujeito, afirma que "a essência da modalidade consiste na relativização da validade dos significados da sentença com um conjunto de mundos possíveis"4.

4 No original: "The essence of modality consists in the relativization of the validity of the sentence meanings to a set of possible worlds.". 
Embora Narrog (2005) não diga de maneira explícita, uma parte crucial desse conceito é a distinção entre não-factual e factualidade negativa, ou seja, uma distinção entre não dizer que algo ocorreu e dizer que algo não ocorreu. Essa distinção, no entanto, pode ser percebida em sua própria definição de modalidade: "Modalidade é uma categoria linguística que se refere ao status factual de um estado-de-coisas. A expressão de um estado-de-coisas é modalizada se este for marcado como indeterminado com respeito ao seu status factual, isto é, nem positivamente, nem negativamente factual" ${ }^{5}$ (NARROG, 2005, p. 184, tradução nossa).

Narrog (2005, p. 182) oferece os seguintes exemplos:

(01) Mary is at home now.

'Mary está em casa agora'.

(02) Mary may be at home now.

'Mary pode estar em casa agora.'

Narrog esclarece que a situação "Mary estar em casa" em (1) não está modalmente marcada e, assim, apresentada como uma situação factual para o tempo a que se refere. Em contraste, a situação em (2) é apresentada como puramente dentro do domínio do pensamento, indeterminada com respeito à sua factualidade. Não se sabe se Mary está ou não em casa.

Outro exemplo oferecido por Narrog (2005, p. 185) mostra a distinção de aspecto e modalidade:

(03) You're telling me you don't love me anymore.

'Você está me dizendo que não me ama mais'.

Nesse exemplo, o aspecto progressivo é utilizado para criar um efeito de trazer para o primeiro plano o dizer de um interlocutor, conforme observado pelo falante, ou seja, o aspecto progressivo neste caso está diretamente ligado à expressão da subjetividade do falante. Com uma definição de modalidade como expressão da subjetividade, esse uso do aspecto progressivo seria considerado uma expressão de modalidade. Por outro lado, levando-se em conta apenas o status factual da sentença, podemos observar que o evento é apresentado como factual e não indeterminado, resultando assim em sua exclusão da categoria modal.

5 No original: "The expression of a state of affairs is modalized if it is marked for being undetermined with respect to its factual status, i.e., is neither positively nor negatively factual.". 
Dessa forma, conclui Narrog (2005), adotar-se o conceito de modalidade como suspensão da factualidade apresenta como vantagem a possibilidade de criação de uma categoria gramatical no mesmo nível de outras como o aspecto, tempo e negação, sem a incoerência de, ao mesmo tempo, incluí-las em si, e sem a abrangência desnecessária decorrente da falta de precisão do conceito de subjetividade.

\section{Análise do Estatuto Factual}

\subsection{A Factualidade em Narrog (2005)}

A noção de factualidade como central à definição de modalidade apresenta diversas vantagens em comparação com outras definições, como a centrada na expressão de subjetividade e a de item fora da proposição, conforme defendido por Narrog (2005). Repetimos aqui o exemplo utilizado para ilustrar a oposição essencial entre sentenças não-modalizadas e modalizadas (NARROG, 2005, p. 182):

(04) Mary is at home now.

'Mary está em casa agora'.

(05) Mary may be at home now.

'Mary pode estar em casa agora.'

Segundo o autor, a situação em (4), 'Mary está em casa agora' não é modalizada, apresentada como "uma situação concretizada, realis, factual e válida para o tempo a que se refere" (NARROG, 2005, p. 182). Já a segunda situação, em (5), é modalizada, isto é, apresentada como pertencente ao domínio do pensamento, aberta com relação à sua concretização.

Ao optar pela expressão factual em vez de real, Narrog (2005) explica uma distinção crucial em sua definição de modalidade. Para o autor, o termo "real" denota apenas parte do que é considerado factual, especificamente, aquilo que existe concretamente e dado no tempo presente. Na concepção de Narrog, eventos não-modalizados podem também pertencer aos tempos passado e futuro. Assim, frases como "Amanhã haverá uma reunião" são apresentadas pelo falante como factuais e, portanto, não-modalizadas.

É importante destacar que, para Narrog (2005), o que importa não é o "mundo real", mas a linguagem. Aquilo que é apresentado como factual por meio da linguagem, não necessariamente corresponde ao "mundo real". Essa distinção é importante para a análise de factualidade, uma vez que, sem ela, o pesquisador poderia assumir, incorretamente, que qualquer afırmação que não possa ser verificada seria modalizada. 
Por fim, uma última importante distinção é com relação à negação. Para Narrog (2005), frases com negativas são negativamente factuais, ou seja, não indeterminadas com relação à factualidade e, portanto, não modais.

\subsection{0 problema da factualidade}

Embora a proposta de Narrog (2005) seja convincente com relação às vantagens de se adotar a (suspensão da) factualidade como noção central para a modalidade, o autor não explicita de que forma é possível estabelecer o estatuto factual das sentenças em questão. Dito de outra forma, quais são os critérios utilizados para definir o estatuto factual dos estados-de-coisas?

Uma proposta encontrada é a de Saurí (2008). Em sua tese de doutorado, a autora propõe uma ferramenta para a análise automática de perfil de factualidade (factuality profiler), chamada De Facto.

O modelo utilizado para a construção do De Facto apresenta dois parâmetros: polaridade e probabilidade. Por meio da polaridade, o informante considera o evento como uma situação que acontece no mundo real (polaridade positiva), que não acontece no mundo real (polaridade negativa) ou como incerta ou não expressa (polaridade não especificada - underspecified). Por meio da probabilidade, o informante expressa seu grau de comprometimento com relação a um evento acontecer (ou não) no mundo real, podendo ser certo, provável, possível, ou não especificado (underspecified).

A combinatória desses dois parâmetros resulta em seis valores completamente comprometidos (ou especificados) - $\langle\mathrm{CT},+\rangle,\langle\mathrm{CT},-\rangle,\langle\mathrm{PR},+\rangle,\langle\mathrm{PR},-\rangle,\langle\mathrm{PS},+\rangle,\langle\mathrm{PS},-\rangle$ -, e dois não especificados - $<C T$, u $>$ e $<U, u>$. Outras combinatórias (por exemplo, $<P R, u>$ ou $<U,+>$ ) parecem ser não aplicáveis. Os seis primeiros valores são bastante familiares no estudo da modalidade epistêmica e se referem a avaliações de que um evento (provavelmente, possivelmente) acontece ou não no mundo real como em "Mary (provavelmente, possivelmente) está em casa".

O valor parcialmente não especificado $<C T$, u $>$ é reservado para casos em que a natureza factual do evento é certa, mas o resultado não claro. O exemplo oferecido por Saurí (2008, p. 33) é o seguinte:

John knows whether Mary came.

'John sabe se Mary veio.' 
Tendo como fonte o informante John, o evento came ('vir') é tido como factualmente certo (indicado pelo verbo 'saber'). John sabe se o evento aconteceu ou não, no entanto, a polaridade do evento é desconhecida, portanto, não especificada.

O valor completamente não especificado $<U$, u > se aplica nas seguintes situações: i. a fonte desconhece o estatuto factual do evento (7a); ii. a fonte não está ciente da possibilidade do evento (7b); ou iii. a fonte não se compromete explicitamente (7c) (SAURÍ, 2008, p. 33):

(07) a. John does not know whether Mary came.

'John não sabe se Mary veio.'

b. John does not know that Mary came.

'John não sabe que Mary veio.'

c. John knows that Paul said that Mary came.

'John sabe que Paul disse que Mary veio'.

Nesses exemplos, John é a fonte relevante para a avaliação do evento came ('vir').

É importante frisar nesse momento a relevância de dois fatores na identificação da factualidade para Saurí (2008): a fonte e o alvo da avaliação.

Nos exemplos anteriores, (6) e (7), a fonte relevante para a avaliação é John. Tendo o falante como fonte, o evento came ('vir') no exemplo (6) seria classificado como <U, u>, uma vez que o falante não se compromete com a avaliação, transferindo a responsabilidade a John. Por outro lado, tendo o falante como fonte, no exemplo (7b), o evento em questão seria classificado como $<\mathrm{CT}$, +>. Nesses exemplos, também, o alvo da avaliação, isto é, o evento em foco na análise factual, foi o verbo came ('vir'), mas, igualmente, se o alvo fosse outro, o resultado da análise factual seria diferente.

Feitas essas observações, passemos à discussão do critério utilizado por Saurí (2008) para a análise factual. Trata-se de um teste de copredicação, em que o contexto original do evento recebe a adição de um segundo fragmento, com um diferente grau de modalidade, mantendo a polaridade original do evento, ou invertendo-o.

Eventos caracterizados como não especificados $\langle U\rangle$ (8) podem ser copredicados com enunciados de contextos de certeza positiva $<\mathrm{CT}+>(10 \mathrm{a})$ e negativa $<\mathrm{CT}->(10 \mathrm{~b})$, em contraste com o exemplo (9), que envolve um evento explicitamente caracterizado como provável <PR> (SAURÍ, 2008, p. 35): 
(8) Iraq has agreed to allow Soviets in Kuwait to leave. (U)

'Iraque concordou em permitir que soviéticos deixem o Kuwait.'

(9) Soviets in Kuwait will most probably leave. (PR)

'Soviéticos muito provavelmente deixarão o Kuwait'.

(10) a. ... They will take the plane tomorrow early in the morning. (CT+)

'Eles tomarão um avião amanhã de manhã cedo.'

b. ... However, most of them decided to remain there. (CT-)

'Contudo, a maioria deles decidiu ficar.'

Eventos caracterizados como certos $\langle\mathrm{CT}\rangle$, por sua vez, são diferenciados de eventos prováveis e possíveis por não poderem ao mesmo tempo ser avaliados como possíveis de polaridade oposta (SAURÍ, 2008, p. 35):

(11) a. Hotels are only thirty (ct+) percent full.

'Hotéis estão apenas trinta por cento cheios.'

b. \#... but it is possible that they aren't (ps-).

'... mas é possível que não estejam.'

(12) a. Nobody believes (ct-) this anymore.

'Ninguém mais acredita nisso.'

b. \#... but it is possible that somebody does (ps+)

'... mas é possível que alguém acredite.'

Em contraste, eventos caracterizados como possíveis <PS $>$ ou prováveis $<$ PR $>$ permitem esse tipo de copredicação (SAURÍ, 2008, p. 36):

(13) a. I think it's not going to change ( $\left.\mathrm{pr}^{-}\right)$for a couple of years.

'Acho que não vai mudar por mais alguns anos.'

b. ... but it could happen otherwise. (ps+)

'... mas pode acontecer o contrário.' 
(14) a. He probably died ( $\mathrm{pr}+$ ) within weeks or months of his capture.

'Ele provavelmente morreu em poucas semanas ou meses após sua captura'

b. ... but it is also possible that the kidnappers kept him alive for a while. (ps-)

'...mas também é possível que os sequestradores o mantiveram vivo por um bom tempo.'

A distinção entre $<\mathrm{PR}>\mathrm{e}<\mathrm{PS}>$ se dá pelo fato de apenas $<\mathrm{PS}>$ aceitar a copredicação com contextos prováveis de polaridade oposta (SAURí, 2008, p. 36):

(15) a. I think it's not going to change (pr-) for a couple of years.

'Eu acho que não vai mudar por alguns anos.'

b. \#... but it probably will. (pr+)

'... mas provavelmente irá'

(16) a. It may not change (ps-) for a couple of years.

'Pode ser que não mude por alguns anos'

b. ... but it most probably will. (pr+)

'... mas provavelmente irá.'

\section{Análise factual dos advérbios modais}

Para a análise dos advérbios modais, partimos da classificação e definição propostas por Neves (2011). Segundo a autora, os advérbios modais 6

[...] compõem uma classe ampla de elementos adverbiais que têm como característica básica expressar alguma intervenção do falante na definição da validade e do valor de seu enunciado: modalizar quanto ao valor de verdade, modalizar quanto ao dever, restringir o domínio, definir a atitude e, até, avaliar a própria formulação linguística. (NEVES, 2011, p. 244).

Como pode ser observado, a definição da autora inclui tanto a noção de factualidade ("valor de verdade"), como a noção de subjetividade ("atitude").

6 Neves (2011) emprega o termo advérbio modalizador. Não será realizada neste texto a distinção entre modal e modalizador, sendo ambos entendidos como relacionados à categoria modalidade. 
Neves (op. cit.) classifica os advérbios modais em epistêmicos ou asseverativos, que indicam uma crença do falante (como certamente, talvez e realmente), deônticos, que apresentam uma obrigação (obrigatoriamente, necessariamente), delimitadores, que delimitam um ponto de vista segundo o qual uma verdade é julgada (historicamente, tecnicamente, quase) e afetivos ou atitudinais, que indicam o estado de espírito do falante (felizmente, francamente).

Outros estudos que empregam o rótulo advérbio modal são os realizados no âmbito do projeto Gramática do Português Falado, como llari et al. (1993) e Castilho e Moraes de Castilho (1992). A classificação desses autores é muito próxima da classificação de Neves, com algumas diferenças de nomenclatura (advérbios de circunscrição, em vez de delimitadores).

No presente trabalho, serão analisados três advérbios considerados por esses autores como modais, a saber, francamente, quase e obrigatoriamente.

As ocorrências para análise foram extraídas do Córpus do Português - Web/Dialect (CPW/D). Esse córpus foi escolhido por apresentar um grande número de textos (cerca de 60 mil páginas da internet), e por não haver nesse córpus uma especificação de gêneros textuais, o que, a princípio, nos permite assumir que as análises realizadas sejam válidas para a língua portuguesa de modo geral.

Iniciaremos a análise com o advérbio francamente. Aplicando-se o teste proposto por Saurí (2008), vemos que o advérbio francamente, em um contexto de polaridade positiva, é incompatível com contextos provável, possível negativo <PR/PS, - > (17a) e certo negativo $<\mathrm{CT}$, - > (17b), tendo o falante como fonte e o evento "estar ficando louca" como alvo. A substituição ${ }^{7}$ do advérbio francamente por possivelmente em (18) mostra como a mesma frase seria compatível com o valor $<\mathrm{PR},->$.

(17) francamente estou ficando louca (CP-W/D - desabafa.com)

a. \# embora possivelmente/provavelmente não esteja

b. \# embora não esteja

7 Embora a aplicação de comutação não seja necessariamente um método comumente empregado em abordagens funcionais, neste trabalho seu uso pode ser considerado vantajoso, uma vez que permite mostrar, por meio da comparação, que a aceitabilidade do enunciado não é algo dependente de um contexto específico. 
(18) possivelmente, estou ficando louca
a. \# embora não esteja
b. embora mais provavelmente não esteja

Em (19), vemos que a frase sem o advérbio francamente é igualmente incompatível, o que indica que esse advérbio não altera o estatuto factual da sentença.

(19) estou ficando louca

a. \# embora possivelmente/provavelmente não esteja

b. \# embora não esteja

Essa incompatibilidade também é detectada em outros usos do advérbio, como em (20):

(20) A única coisa que eles têm feito é admitir francamente os seus pecados (CP-W/D bjnewlife.org)
a. \# embora possivelmente não os tenham admitido

Igualmente, com a substituição por possivelmente, em (21), mostra compatibilidade com $<P R,->$ e mantém o mesmo estatuto da frase sem o advérbio (22):

(21) A única coisa que eles possivelmente tenham feito é admitir os seus pecados

a. embora mais provavelmente não os tenham admitido

(22) A única coisa que eles têm feito é admitir os seus pecados

a. \# embora possivelmente não os tenham admitido

Assim, podemos concluir que o advérbio francamente não suspende a factualidade do evento modificado, não sendo, portanto, um advérbio modal.

Passamos agora para a análise do advérbio quase. Em seu uso mais comum, quase aproxima uma Quantidade, definida (23) ou indefinida (24):

(23) As autoridades cortaram e enterraram as partes do animal a uma profundidade de quase 5 metros e, mesmo assim, algumas acabaram sendo desenterradas e devoradas por aves. (CP-W/D - 102fmnatal.com.br) 
(24) A maioria dos itens podem ser considerados inúteis, mais elas garantem que usam quase tudo, afinal podem ocorrer muita coisa durante o dia. (CP-W/D - 007blog.net)

Como esse uso não tem escopo sobre um evento, os testes propostos por Saurí (2008) parecem não ser aplicáveis. Sendo assim, podemos concluir que se trata de um uso nãomodal.

Em um segundo uso de quase, que tem escopo sobre um evento, o falante parece qualificar o evento como factualmente negativo, uma vez que a inferência que se pode fazer é a de que se um evento é marcado como aproximadamente realizado, quer dizer que não se realizou:

(25) Quase perdi o carro se não tivesse agido rápido. (CP-W/D - 007blog.net)

Essa leitura factual (de valor certo) é inicialmente suportada pelo fato de que esse uso se mostra incompatível com contextos possível e provável positivos $<\mathrm{PS} / \mathrm{PR},+>$ :

(26) \#Mas é possível que ele esteja perdido

(27) \#Mas é provável que ele esteja perdido

Contudo, algumas observações devem ser feitas: em primeiro lugar, quase pode atuar sobre um evento certo de polaridade negativa, como em (28); em segundo lugar, quase pode ser combinado com um contexto de factualidade de mesmo valor, como em (29), o que não poderia ocorrer, caso a factualidade do evento fosse simplesmente certa (30):

(28) Quase não houve tempo para nova saída (CP-W/D - 100anosdemariofilho.com)

(29) Quase perdi o carro, mas não perdi

(30) *Não perdi o carro, mas não perdi

Assim, o valor factual dos eventos modificados por quase não deve ser entendido como certo, mas como contrafactual. latridou (2000, p. 231) defıne construções contrafactuais como "construções que expressam o significado de que o falante acredita que uma certa proposição não é verdadeira". 
O contrafactual expresso por quase deve ser diferenciado do negativamente factual. Segundo Gerstenberg e Tenenbaum (2016), para um evento quase ter acontecido, sua probabilidade de ocorrência atual deve ser zero (impossível), mas sua probabilidade (subjetiva) em algum momento anterior deveria ter sido alta. Isso explica porque o evento pode ser seguido de uma repetição aparentemente idêntica de mesma polaridade, como vimos no exemplo (29).

Embora esses autores utilizem expressões como "probabilidade" e "acreditar", o advérbio quase não deve ser entendido como uma expressão modal de possibilidade e probabilidade, já que se mostra incompatível com contextos de valor factual $<P R, P S$, oposto>, como vimos nos exemplos (26) e (27). Em comparação, veja-se o exemplo (31), a seguir, em que o evento é modalizado por possivelmente:

(31) Possivelmente não perdi o carro, mas é mais provável que ele esteja perdido.

Por fim, note-se como uma outra construção contrafactual comporta-se da mesma forma que a construção com quase:

(32) Teria perdido o carro se não tivesse agido rápido

a. \#Mas é possível que ele esteja perdido.

b. Mas não perdi.

O advérbio quase, portanto, funciona apenas como um modificador de quantidades ou um modificador contrafactual, não sendo, portanto, classificado como um advérbio modal.

Por fim, analisamos o advérbio obrigatoriamente. A análise desse advérbio é um pouco mais complicada que os advérbios analisados até então neste estudo, pois a maior parte das ocorrências em que encontramos obrigatoriamente envolvem eventos já modalizados, como (33) abaixo:

(33) Pronunciamentos CPC tornam-se Normas Brasileiras de Contabilidade e, desta forma, devem ser obrigatoriamente observados pelas organizações, tendo em vista os seus efeitos. (CP-W/D - 4mail.com.br)

Nessa ocorrência, o evento "ser observado pelas organizações" já é marcado como factualmente indefinido pelo verbo modal dever. Nesse caso, o advérbio obrigatoriamente apenas especifica o valor modal como obrigatório. Um forte indício dessa interpretação é a possibilidade de se coordenar o modal com preferencialmente, juntamente com obrigatoriamente ${ }^{8}$ :

8 Optou-se aqui pela utilização de uma ocorrência extraída fora do Córpus do Português, pois não foi encontrada nele nenhuma coocorrência dos advérbios preferencialmente e obrigatoriamente. 
(34) A Lei no 605/1949 estabelece que o repouso semanal remunerado deve ser preferencialmente, e não obrigatoriamente aos domingos. (https://br.answers.yahoo. com/question/index?qid=20111105215106AA0E2t8)

Essa especificação do valor deôntico ocorre também em ocorrências em que o advérbio obrigatoriamente precede o modal:

(35) Se você colocar cinco senadores entre os melhores, obrigatoriamente tem que incluir Ana Amélia Lemos. (CP-W/D - agenda2020.com.br)

O advérbio obrigatoriamente pode por si só, como veremos na ocorrência a seguir, modalizar o evento deonticamente, instaurando uma obrigação legal, sendo compatível tanto com copredicações certas positivas como negativas, bem como prováveis e possíveis de polaridade oposta, caracterizando a factualidade como indefinida:

(36) o auxílio-doença paga 91\% da média de contribuições, e apenas para o segurado que fica mais do que 15 dias incapacitado para o trabalho; obrigatoriamente vai passar pela perícia médica do INSS (CP-W/D - atdigital.com.br)
a. ... João passou pela perícia e assim receberá o auxílio. $(C T,+)$
b. ... João não passou pela perícia e, portanto, não receberá o auxílio. (CT, -)
c. ...João possivelmente/provavelmente não passou pela perícia (PR/PS, -)

O advérbio obrigatoriamente pode também instaurar uma necessidade física ou lógica. Nesses contextos, a copredicação certa de polaridade oposta e a possível/provável se tornam incompatíveis:

(38) mas sabe que isso não é bem assim, incremento de giro necessita obrigatoriamente de mais combustível (CP-W/D - autoentusiastas.blogspot.com)

a. ? Houve um incremento de giro, mas não houve necessidade de combustível

b. ? Houve um incremento de giro, portanto possivelmente/provavelmente necessitou de mais combustível

(39) se um artigo é comprado por $\mathrm{R} \$ 1,00$, obrigatoriamente o vendedor obteve $\mathrm{R} \$ 1,00$ de renda. (CP-W/D - blog.bussoladoinvestidor.com.br)

a. ? $O$ artigo foi vendido por $\mathrm{R} \$ 1,00$, mas o vendedor não obteve $\mathrm{R} \$ 1,00$ de renda.

b. ?0 artigo foi vendido por $\mathrm{R} \$ 1,00$, portanto o vendedor possivelmente/ provavelmente obteve $\mathrm{R} \$ 1,00$ de renda. 
A obrigação física ou lógica pode ainda ser negada, o que parece suspender a factualidade do evento, já que sua copredicação é compatível tanto em contextos certos de qualquer polaridade, como possíveis/prováveis.

(40) Após a fecundação da fêmea pelo macho ela irá colocar em média de 4 a 7 ovos no ninho. Não obrigatoriamente todos estarão fecundados. (CP-W/D - universodascaturras. blogspot.com)

a. Neste caso, todos os ovos estão fecundados.

b. Neste caso, não são todos os ovos que estão fecundados. fecundados.

c. Neste caso, possivelmente/provavelmente não são todos os ovos que estão

Embora o teste de copredicação indique que a obrigação física/lógica sob o escopo da negação seja uma forma de expressão da modalidade, já que o valor de factualidade é indefinido, esse uso do advérbio se assemelha bastante a usos aspectuais que avaliam quantitativamente um estado-de-coisas, como os marcadores habituais (cf. HENGEVELD; MACKENZIE, 2008). Substituindo-se não obrigatoriamente por normalmente, em geral e outras construções adverbiais similares, os mesmos enunciados copredicados em (40) podem ser igualmente aplicados.

Assim, o advérbio obrigatoriamente pode funcionar como apenas um especificador do valor deôntico realizado por outro modal, mas também, por si só, pode expressar modalidade, dependendo do tipo de necessidade envolvida: necessidades legais ou morais levam à suspensão da factualidade, enquanto necessidades físicas ou lógicas levam à não suspensão da factualidade, exceto quando negadas, caso em que os testes de copredicação sugerem a suspensão da factualidade.

\section{Resumo da análise}

O resultado da análise é resumido no quadro a seguir, em que os sinais de (+) representam compatibilidade e (-) incompatibilidade nos testes de copredicação: 
Quadro 1. Classificação de advérbios modais por meio de testes de copredicação.

\begin{tabular}{|l|l|l|l|l|}
\hline \multicolumn{1}{|c|}{ Advérbio } & \multicolumn{1}{|c|}{$\begin{array}{c}\text { Contexto } \\
\text { Certo } \\
\text { polaridade } \\
\text { oposta }\end{array}$} & $\begin{array}{c}\text { Contexto } \\
\text { Provável/ } \\
\text { Possível } \\
\text { polaridade } \\
\text { oposta }\end{array}$ & Valor factual & Modal \\
\hline Francamente & - & - & Certo & Não \\
\hline Quase & + & - & Contrafactual & Não \\
\hline $\begin{array}{l}\text { Obrigatoriamente } \\
\text { (Legal/Moral) }\end{array}$ & + & + & $\begin{array}{l}\text { Não } \\
\text { especificado }\end{array}$ & Sim \\
\hline $\begin{array}{l}\text { Obrigatoriamente } \\
\text { (Físico/Lógico) }\end{array}$ & - & - & Certo & Não \\
\hline $\begin{array}{l}\text { Não } \\
\text { Obrigatoriamente } \\
\text { (Físico/Lógico) }\end{array}$ & + & + & $\begin{array}{l}\text { Não } \\
\text { especificado }\end{array}$ & Sim \\
\hline
\end{tabular}

A análise foi realizada utilizando ocorrências extraídas do Córpus do Português (DAVIES, 2006), tendo sido escolhidos três advérbios: francamente, quase e obrigatoriamente. 0 teste de copredicação com o advérbio francamente mostrou que esse advérbio apresenta as mesmas restrições de copredicação de enunciados de valor certo, na classificação de Saurí (2008), tanto em usos mais concretos, de menor escopo, como em A única coisa que eles têm feito é admitir francamente os seus pecados, como em usos mais subjetivos, em que o falante avalia, por meio do advérbio, o seu próprio ato de fala, como em francamente estou ficando louca.

A análise de quase, por sua vez, mostra que esse advérbio, similarmente a predicações de valor certo, é incompatível com predicações de valor possível e provável. No entanto, predicações com quase podem ser combinadas com predicações de valor certo e polaridade oposta. Seguindo latridou (2000) e Gerstenberg e Tenenbaum (2016), classificamos esse novo valor factual como contrafactual.

Por fim, a análise de obrigatoriamente mostrou que, em enunciados não previamente modalizados, o estatuto factual depende do tipo de obrigação instaurada: ao tratar-se de deveres morais ou legais, o valor factual é o mesmo de enunciados de probabilidade não especificada, ou seja, sua factualidade é suspensa; quando o dever ou obrigação vem de uma necessidade física ou lógica, a factualidade não é suspensa, comportando-se da mesma forma que enunciados de valor certo; contudo, sob o escopo da negação, o valor 
factual é não especificado. Essa diferença parece ser devida ao próprio funcionamento da lógica: aquilo que não é logicamente necessário é, portanto, possível.

Dessa forma, a princípio, os testes de copredicação propostos por Saurí (2008) parecem servir bem à tarefa de classificação dos advérbios modais, segundo a conceitualização proposta por Narrog (2005), de modalidade como suspensão da factualidade. Contudo, conforme indicamos na análise, a suspensão de factualidade mostrada pelo advérbio obrigatoriamente instaurando necessidades físicas ou lógicas sob o escopo da negação parece muito próxima de usos aspectuais de habitualidade, que apresenta o mesmo comportamento em testes de copredicação. Dado que Narrog (2005) descarta usos temporais da categoria da modalidade, a adequação dos testes de copredicação para a classificação de itens modais não pode ser afırmada neste momento, necessitando de um estudo mais abrangente, que envolva, por exemplo, advérbios marcadores de aspecto quantitativo de evento, como habitualmente, normalmente etc.

\section{Considerações finais}

Os testes de copredicação analisados no presente trabalho, a princípio, parecem ser uma ferramenta útil para a classificação dos advérbios modais, permitindo ao pesquisador uma forma mais objetiva para a realização dessa empreitada, baseando-se em critérios claramente definidos.

Esses testes, porém, apresentam algumas desvantagens. A primeira é a de que, pela própria definição dos testes, os advérbios provavelmente e possivelmente não podem ser testados, pois são utilizados nas copredicações. A segunda, mais relevante, é a de que os testes requerem um conhecimento profundo da língua examinada, já que os testes se baseiam na aceitabilidade do enunciado, dificultando, portanto, o trabalho tipológico. Por fim, o comportamento do advérbio obrigatoriamente, sob o escopo da negação, parece indicar a inadequação dos testes de copredicação, já que seu comportamento se assemelha a usos aspectuais. Esse comportamento pode, inclusive, apontar para a inadequação do conceito de modalidade como suspensão da factualidade.

Este ponto, talvez, seja o mais relevante no uso de testes de copredicação para o estudo da modalidade. Se por um lado, noções como a subjetividade certamente são abrangentes demais para se basear o conceito de modalidade como categoria gramatical a par de outras como o tempo e o aspecto, por outro, a suspensão da factualidade não parece ser característica exclusiva dessa categoria.

É necessário observar, entretanto, algumas peculiaridades de obrigatoriamente, comparando-se com outros advérbios como talvez, um advérbio unanimemente, acredito, classificado como modal. A primeira observação é a de que os usos de obrigatoriamente que suspendem a factualidade são mais dependentes de contexto; em diversos 
contextos, obrigatoriamente apenas especifica o tipo de obrigação instaurada por outro modal e a suspensão da factualidade depende ainda do tipo de obrigação instaurada, o que não ocorre com talvez, que sempre marca uma possibilidade assumida pelo falante. A segunda observação é a de que talvez, diferentemente de obrigatoriamente, não depende de outro item gramatical para realizar a função de suspender a factualidade.

É possível que o que observamos aqui seja uma manifestação do que Aikhenvald (2004, p. 6) chama de "extensão epistêmica". De acordo com a autora, os evidenciais (marcas gramaticais da fonte da informação contida em um enunciado) "podem adquirir significados secundários - de confiabilidade, probabilidade e possibilidade". Para a autora, essa extensão epistêmica explica o fato de que a evidencialidade e a modalidade sejam frequentemente tratadas como uma única categoria.

Se aceitarmos que a extensão epistêmica cria um ponto de intersecção entre a modalidade e a evidencialidade e que essas são, realmente, categorias distintas, é possível manter-se a posição de que a suspensão da factualidade é, de fato, uma noção fundamental para a categoria da modalidade.

Assim, ainda que os testes de copredicação não sejam uma ferramenta definitiva para a classificação das formas de expressão da modalidade, certamente eles podem nos ajudar a avançar nosso entendimento de seu estatuto como categoria gramatical.

\section{REFERÊNCIAS}

AIKHENVALD, A. Y. Evidentiality. Oxford, England: Oxford University Press, 2004.

CASTILHO, A. T.; MORAES DE CASTILHO, C. M. Advérbios modalizadores. In: ILARI, R. (org.). Gramática do português falado. Campinas: Ed. UNICAMP, 1992. p. 213-260.

DAVIES, M. Corpus do português: One billion words, 4 countries, 2016. Disponível em: http://www.corpusdoportugues.org/web-dial/. Acesso em: 06 jun. 2019.

DIK, S. The theory of functional grammar. Pt 1. The Structure of the Clause. Dordrecht: Foris Publications, 1989.

DIK, S. The theory of functional grammar. Pt 2: Complex and derived constructions. Edited by Kees Hengeveld. Berlin, New York: Mouton de Gruyter, 1997.

FILLMORE, C. The case for case. In: BACH, E.; HARMS, R. T. (ed.). Universals in linguistic theory. Nova York: Holt, Rinehart and Winston Inc., 1868. p. 1-88. 
GERSTENBERG, T.; TENENBAUM, J. B. Understanding "almost": Empirical and computational studies of near misses. In: PAPAFRAGOU, A.; GRODNER, D.; MIRMAN, D.; TRUESWELL, J. C. (ed.). Proceedings of the 38th Annual Conference of the Cognitive Science Society. Austin, TX: Cognitive Science Society, 2016. p. 2777-2782.

HENGEVELD, K.; MACKENZIE, J. L. Functional discourse grammar: a typologically based theory of language structure. Oxford: Oxford University Press, 2008.

IATRIDOU, S. The grammatical ingredients of counterfactuality. Linguistic inquiry, v. 31, n. 2, p. 231-270, 2000.

ILARI, R. et al. Considerações sobre a posição dos advérbios. In: CASTILHO, A. T. de (org.). Gramática do português falado: a ordem. v. 1. 3. ed. Campinas: EDUNICAMP, 1993. p. 63141.

KIEFER, F. Presidential address - modality and pragmatics. Folia linguistica, v. 31, n. 3-4, p. 241-253, 1997.

LYONS, J. Introduction to theoretical linguistics. Cambridge: Cambridge University Press, Cambridge, 1968.

LYONS, J. Semantics. v. 2. Cambridge: Cambridge University Press, 1977.

NARROG, H. On defining modality again. Language Sciences, v. 27, n. 2, p. 165-192, 2005.

NEVES, M. H. M. Gramática de usos do português. 2. ed. São Paulo: Editora da UNESP, 2011.

PALMER, F. R. Mood and modality. Cambridge: Cambridge University Press, 1986.

PALMER, F. R. Mood and modality: basic principles. In: BROWN, K., MILLER, J. (ed.). Concise Encyclopedia of Grammatical Categories. Oxford: Elsevier, 1998. p. 229-235.

PALMER, F. R. Mood and modality, second edition. Cambridge: Cambridge University Press, 2001.

PAPAFRAGOU, A. Modality: issues in the semantics-pragmatics Interface. Oxford: Elsevier, 2000.

SAURÍ, R. A factuality profiler for eventualities in text. 2008. Tese (Ph.D) - Universidade Brandeis, Waltham, MA, 2008.

van der AUWERA, J.; PLUNGIAN, V. A. Modality's semantic map. Linguistic typology, v. 2, n. 1, p. 125-139, 1998. 